\title{
Turismo, planeamento e desenvolvimento sustentável ${ }^{1}$
}

\author{
Tourism, planning and sustainable development
}

\author{
Maria Noémi Marujo (MARUJO, M. N.) \\ Paulo Carvalho (CARVALHO, P.) ${ }^{* *}$
}

\begin{abstract}
RESUMO - A articulação entre o planeamento e o desenvolvimento turístico (ou do turismo) sustentável, tendo em vista satisfazer as necessidades económicas, sociais e estéticas sem colocar em causa a continuidade dos recursos turísticos (designadamente culturais e ecológicos), remete para a relevância do processo de planeamento. O planeamento do turismo configura uma ferramenta estruturante da política de desenvolvimento sustentável e, por isso, ocupa um lugar decisivo no processo de concepção e implementação de estratégias de desenvolvimento. $\mathrm{O}$ presente artigo pretende contribuir para aprofundar a análise teórica e conceptual em torno da trilogia "turismo/planeamento/desenvolvimento sustentável”, utilizando como suporte metodológico uma revisão da bibliografia mais relevante neste domínio.
\end{abstract}

Palavras-chave: Turismo; Planeamento; Desenvolvimento Sustentável.

ABSTRACT - The link between the planning and the sustainable tourism development in order to satisfy the economic, social and aesthetic needs without risking the continuity of the tourism resources (including cultural and ecological resources), remits to the relevance of the planning process. The tourism planning configures a structuring tool for sustainable development policy and therefore occupies a central place in the process of designing and implementation of development strategies. This paper intend to contribute to deepen the theoretical and conceptual analysis around the trilogy "tourism/planning/sustainable development", using as methodological support a review of relevant literature in this field.

Key words: Tourism; Planning; Sustainable Development.

\footnotetext{
1 Versão publicada em idioma português de Portugal.

* Licenciada em Ciências da Comunicação. Mestre em Sociologia e Diplomada em Estudos Avançados Turismo, Lazer e Cultura (Ramo Turismo e Desenvolvimento). Doutoranda em Turismo na Universidade de Évora. Docente do Curso de Turismo da Universidade de Évora (Portugal). Endereço para correspondência: Departamento de Sociologia da Universidade de Évora. Largo dos Colegiais, n. 2 (Apartado 94). 7002-554 - Évora - Portugal. E-mail: noemi@uevora.pt

** Doutor em Geografia. Mestre em Geografia Humana. Professor Doutor do Departamento de Geografia da Universidade de Coimbra (Portugal). Investigador do Centro de Estudos de Geografia e Ordenamento do Território da Universidade de Coimbra. Docente do Programa de Doutoramento em Turismo, Lazer e Cultura da Universidade de Coimbra. Endereço para correspondência: Faculdade de Letras da Universidade de Coimbra. Largo da Porta Férrea. 3004-530 - Coimbra - Portugal. E-mail: paulo.carvalho@fl.uc.pt
} 


\section{INTRODUÇÃO}

O turismo, actualmente, é um dos fenómenos mais importantes do ponto de vista político, económico, ambiental e sociocultural. Deixou de ser visto apenas como um sinónimo de lazer e passou a assumir um papel de agente social nas sociedades em que se desenvolve (MARUJO, 2008). Com o desenvolvimento das tecnologias de informação e comunicação, o turismo tornou-se numa das mais importantes actividades da economia global, sendo considerado por muitas entidades públicas como a "tábua de salvação” para o desenvolvimento de muitos países, regiões ou localidades. Presentemente, o turismo tornou-se um “objecto de desejo para muitas regiões" (SILVEIRA, 2002, p. 87). De facto o turismo, graças à sua importância económica e sociocultural, é um importante pilar para a economia e desenvolvimento de muitas regiões, dado que arrasta consigo um conjunto de actividades bastante relevantes e, por isso, os governos regionais e locais interessados em promover o desenvolvimento local e regional vêem no turismo um forte aliado na procura desse desenvolvimento. Por outro lado, o planeamento assumiu "um papel de maior relevância no desenvolvimento turístico à medida que os governos passaram a reconhecer não apenas que o sector gera um largo espectro de impactos, mas também que pode ter um importante papel no crescimento e revitalização social e cultural” (OMT, 2003, p. 215). Se o turismo é considerado um dos mais importantes agentes de mudança em qualquer sociedade, então ele não pode deixar de evoluir sem um planeamento. No entanto, este planeamento deve ser estratégico, integrador, participativo e pluralista no sentido de envolver as dimensões sociais, económicas e físicas (GUNN, 1994). Significa isto que, há diversos tipos de planeamento turístico, e que a sua aplicação dependerá da realidade de cada país, região ou localidade, ou seja, da localização, do mercado turístico, dos recursos específicos e das políticas adoptadas (INSKEEP, 1991).

\section{TURISMO, DESENVOLVIMENTO SUSTENTÁVEL E PLANEAMENTO}

Alguns investigadores (BARRETTO, 2005; COSTA, 2001; RUSCHMANN, 2008) reconhecem que a actividade turística tem, de facto, uma importância relevante na 
economia das áreas receptoras, mas também admitem que ela provoca muitas vezes uma degradação ambiental nessas áreas. Esta questão, levou à adopção de novas formas de turismo como o designado turismo sustentável entendido, pela OMT (2003), como aquele que satisfaz as necessidades dos turistas, das regiões receptoras ao mesmo tempo que protege e potencia novas oportunidades para o futuro.

O conceito de desenvolvimento sustentável do turismo é essencialmente dividido em duas escolas de pensamento: o produto e as abordagens da indústria (GODFREY, 1996). Segundo o autor, a antiga escola é representada pela literatura sobre o desenvolvimento do turismo sustentável ou turismo sustentável, onde a sustentabilidade é vista como uma alternativa ao turismo de massa. "De um modo geral, a abordagem do produto ilustra três temas gerais: a investigação sobre os conceitos gerais; a pesquisa sobre as estratégias de desenvolvimento e a investigação sobre o comportamento do turismo” (GODFREY, 1996, p. 62). A abordagem da indústria representa a literatura em que os seus praticantes argumentam que o turismo de massa é inevitável e, por isso, deve ser feito ensaios para fazer todo o turismo mais sustentável. Trata-se de uma abordagem que "procura modificar as empresas do turismo e as questões do desenvolvimento do turismo de massa através de uma abordagem compreensiva, sistemática e orientada para a comunidade [...]” (GODFREY, 1996, p. 63). A maior dificuldade destas duas escolas de pensamento é que elas representam "demonstrações ilusórias em vez de casos reais específicos de sustentabilidade” (KNOWLES; DIAMANTIS e EL-MOURHABI, 2004, p. 146).

Segundo Inskeep (1991, p. 461) o desenvolvimento sustentável do turismo pode ser percebido como "uma forma de conhecer e satisfazer as necessidades presentes dos turistas e das regiões receptoras, protegendo e garantindo as oportunidades futuras [...]”. Beni (1997) também defende que o turismo sustentável deve pressupor a viabilidade económica e social, privilegiando simultaneamente a cultura local e o ambiente. Portanto, e segundo a OMT (2003), a noção de turismo sustentável deve levar em conta um modelo de desenvolvimento económico que permita: melhorar a qualidade de vida das comunidades anfitriãs; melhorar a qualidade de vida com benefícios económicos e sociais não só para os residentes, mas também para as empresas; promover uma qualidade elevada na experiência do visitante; manter a qualidade do ambiente da qual depende não só a comunidade anfitriã, mas também o visitante; 
assegurar uma distribuição equitativa tanto dos benefícios como dos custos; encorajar a compreensão dos impactos do turismo no ambiente cultural, humano e material; melhorar as infra-estruturas sociais e de cuidados de saúde. Nesta linha, Ruschmann (2008) argumenta que o turismo sustentável deve englobar a existência de turistas mais responsáveis, que a sua interacção com as comunidades receptoras no campo social, cultural e ambiental seja de uma forma equilibrada. Sachs (1993) afirma que o desenvolvimento sustentável deve ser implementado por uma metodologia de planeamento de forma a ser um espaço de aprendizagem social e que possa reflectir uma síntese pedagógica. Segundo o autor, o turismo sustentável está fundamentado nos seguintes princípios de sustentabilidade:

a) Sustentabilidade social: fundamentada no estabelecimento de um processo de desenvolvimento que conduza a um padrão estável de crescimento, com uma redução das actuais diferenças sociais;

b) Sustentabilidade cultural: consolidada na necessidade de procurar soluções de âmbito local através das potencialidades das culturas específicas, levando em consideração a identidade cultural e o modo de vida local, bem como a participação da população nos processos de decisão e na formulação de planos de desenvolvimento turístico;

c) Sustentabilidade ecológica: apoiada na teoria de que o desenvolvimento turístico deve limitar o consumo dos recursos naturais, e provocar poucos danos aos sistemas de sustentação da vida;

d) Sustentabilidade económica: possibilitar o crescimento económico para as gerações actuais, bem como o manuseamento responsável dos recursos naturais que deverão ter o papel de satisfazer as necessidades das gerações futuras;

e) Sustentabilidade espacial: baseada na distribuição geográfica mais equilibrada dos assentamentos turísticos de forma a evitar exceder a capacidade de carga;

f) Sustentabilidade política: alicerçada na negociação da diversidade de interesses envolvidos em questões fundamentais que vão do âmbito local ao global.

Assim, para Sachs (1993), a sustentabilidade só poderá ser impulsionada através da operacionalização de um modelo de planeamento que possa privilegiar todas as suas dimensões. É óbvio que o conceito de desenvolvimento sustentável aplicado ao turismo 
funciona como uma estratégia saudável para a procura de uma integração entre uso turístico, melhoria das condições de vida das comunidades locais e preservação do meio ambiente. Todavia, se esse conceito não for articulado com as “[...] políticas e práticas do planeamento territorial do turismo a nível local, a sustentabilidade não passa de retórica” (SILVEIRA, 2002, p. 88). Portanto, de acordo com Carvalho (2009), e no caso do turismo, as práticas de planeamento e gestão sustentável do turismo são factores essenciais para a sustentabilidade dos lugares e a exequibilidade do turismo. Ou seja, o autor afirma que "o planeamento do turismo é uma ferramenta estruturante da política de desenvolvimento sustentável e por isso ocupa um lugar decisivo no processo de concepção e implementação de estratégias de desenvolvimento (CARVALHO, 2009, p. 1421). Assim sendo, o planeamento é indispensável para o desenvolvimento do turismo sustentável.

\section{PLANEAMENTO DO TURISMO}

O planeamento, segundo Mason (2003), pode ser usado em diferentes contextos geográficos (urbano e rural), bem como ser aplicado em diversas escalas (local, regional e nacional). O planeamento é sempre um “instrumento do poder” (VIEIRA, 2007, p. 29), pois quem planeia antevê o futuro, quantifica-o e orienta-o. A amplitude e diversidade dos conceitos de planeamento fazem com que seja difícil definir esta actividade com exactidão. De uma forma geral, o planeamento pode ser entendido como um conjunto de actividades que “envolve a intenção de estabelecer condições favoráveis para alcançar objectivos propostos. Ele tem por objectivo o aprovisionamento de facilidades e serviços para que uma comunidade atenda aos seus desejos e necessidades” (RUSCHMANN, 2008, p. 83). Pode também ser percebido como o processo que visa estabelecer uma visão estratégica para uma área que reflecte os objectivos da comunidade e de o implementar através da identificação de padrões preferenciais do uso do território e de estilos apropriados de desenvolvimento (DREDGE, 1999) ou ainda encarado do ponto de vista governamental como "um processo que estabelece objectivos, define linhas de acção e planos detalhados para atingi-los, e determina os recursos necessários à sua consecução” (BENI, 1997, p. 110). 
Este autor acrescenta ainda que o planeamento consiste num processo contínuo, permanente e dinâmico.

No campo do turismo, o planeamento possui diversos conceitos. É caracterizado por uma gama de significados, aplicações e usos (WILLIAMS, 2009), e estudado de acordo com as diferentes visões dos investigadores. Enquanto alguns autores centram a sua definição nos objectivos, outros dão ênfase à leitura da realidade social, às etapas ou processos ou, então, ao desenvolvimento integrado. Para Getz (1986), o planeamento do turismo é entendido como um processo baseado na análise e avaliação, que visa optimizar o potencial da contribuição da actividade turística para a qualidade ambiental e o bem-estar humano. Numa outra visão, o planeamento turístico pode ser entendido numa escala regional como "um esforço que visa atingir o melhor padrão espacial possível de desenvolvimento” (TOSUN e JENKIS, 1996, p. 520). Henriques (2003, p. 205) ressalta que o planeamento turístico "tende a ser uma amálgama de considerações económicas, sociais e ambientais que reflectem a diversidade de factores que influenciam o desenvolvimento do sector”.

Como um campo geral de pesquisa, “o planeamento turístico tem espelhado tendências mais amplas dentro das tradições de planeamento urbano e regional (ex: GETZ, 1986; HALL, 2004) principalmente porque se focalizou no planeamento de destinos em vez do planeamento de negócio do turismo individual” (HALL e PAGE, 2006, p. 396). Hall (2004) frisa que, e de modo a acompanhar as novas exigências da actividade turística, o foco e os métodos do planeamento turístico sofreram alterações no curso da história. Hoje, “o planeamento turístico, portanto, ocorre de várias maneiras (desenvolvimento, infra-estrutura, uso do solo e de recursos, organização, recursos humanos, divulgação e marketing); estruturas (outro governo, organizações quase governamentais e não-governamentais); escalas (internacionais, transnacionais, nacionais, regionais, locais e sectoriais) e em diferentes escalas de tempo (para desenvolvimento, implementação, avaliação e realização satisfatória dos objectivos de planeamento)” (HALL e PAGE, 2006, p. 396). Actualmente, os planeadores governamentais admitem que o turismo pode ser utilizado como uma actividade revitalizadora para as economias regionais, e que pode incentivar o desenvolvimento sócio-económico e a promoção de benefícios à população de uma região ou localidade (ARAÚJO e BRAMWELL, 2004). 
O planeamento não é uma actividade recente, pois é possível encontrar formas notáveis de planeamento em todas as civilizações e períodos históricos (COSTA, 2003). Segundo este autor, e no que diz respeito ao planeamento do turismo, a sua origem e expansão estão ligadas à Revolução Industrial e ao consequente desenvolvimento económico, urbano e social desse período. O autor frisa ainda que o aparecimento de um campo identificável e personalizado do planeamento turístico pode ser observado somente após 1920, com a publicação sistemática na Inglaterra de legislação especificamente relacionada com o turismo (COSTA, 2001). No entanto, o planeamento do turismo só ganhou importância a partir da década de 80, especialmente marcada pelo acelerar de um processo de mudança, amadurecimento e de autonomia do planeamento turístico (HENRIQUES, 2003). Neste período, Getz (1986) deu um contributo marcante para o planeamento do turismo, ou seja, numa revisão da literatura sobre 150 modelos do planeamento turístico, o autor concluiu que "o planeamento do turismo era predominantemente orientado para o desenvolvimento do projecto, com base em processos de planeamento para a resolução de problemas. Muitas vezes, é uma definição restrita e carece de abrangência” (GETZ, 1986, p. 31). Em 1987, o autor ${ }^{2}$ identificou no domínio do planeamento turístico quatro abordagens:

a) Fomento: utilizado no desenvolvimento e planeamento turístico desde que se iniciou o turismo de massa;

b) Abordagem económica orientada para a indústria: o planeamento turístico deve centrar as suas atenções nos factores económicos, impulsionadores do incremento do lucro que passa a ser visto como prioritário em relação aos problemas sociais e ecológicos;

c) Abordagem físico-espacial: teve origem no trabalho dos geógrafos, planeadores do uso do solo urbano e regional e conservacionistas que defendem uma abordagem racional para o planeamento dos recursos naturais;

d) Abordagem orientada para o bem-estar da comunidade: defende o máximo de envolvimento da comunidade local no processo de planeamento (HALL; PAGE, 2006).

\footnotetext{
${ }^{2}$ GETZ, D. Tourism planning and research: Traditions, models and futures. In: AUSTRALIAN TRAVEL RESEARCH WORKSHOP, Bunbury, Western Australia, 1987, 5-6 nov.
} 
No turismo, o planeamento é uma condição necessária para a viabilidade, a organização e a sustentabilidade da própria actividade (CARVALHO, 2009). Para Williams (2009), o planeamento do turismo engloba os seguintes objectivos:

a) Permite um mecanismo para uma disposição estruturada de equipamentos turísticos e infra-estruturas associadas ao longo de grandes áreas geográficas;

b) A coordenação da natureza fragmentada do turismo, principalmente em relação ao transporte, alojamento, marketing e recursos humanos;

c) A intervenção na conservação dos recursos e a maximização dos benefícios para a comunidade local;

d) Um mecanismo para a distribuição e redistribuição dos investimentos relacionados com o turismo e os benefícios económicos;

e) A integração do turismo em sistemas de planeamento dá à indústria um significado político (uma vez que a maior parte dos sistemas de planeamento são sujeitos a influências e controle político) e além disso fornece uma medida do estatuto e legitimidade para uma actividade que nem sempre foi considerada seriamente como uma força para a mudança económica e social.

Por outro lado, e no caso das comunidades, o planeamento turístico comunitário deve reconhecer que na satisfação das necessidades locais também é possível satisfazer as necessidades dos visitantes (HENRIQUES, 2003; HALL, 2004). Sublinhe-se que o planeamento turístico comunitário “é uma resposta à necessidade de desenvolver directrizes de maior aceitação social para a expansão do sector” (HALL, 2004, p. 54). O autor considera que, apesar do planeamento turístico comunitário se apresentar na literatura como algo atractivo, existem factores que dificultam a sua aplicação em termos práticos. Logo para este autor, uma das maiores dificuldades na implementação de uma abordagem comunitária no planeamento turístico está sobretudo na natureza política do processo do planeamento. Assim sendo, defende que uma abordagem comunitária no planeamento turístico "implica a necessidade de parceria ou controle do processo de desenvolvimento turístico” (HALL, 2004, p. 56). No entanto, ressalta que essa abordagem comunitária não tem sido geralmente adoptada pelas autoridades governamentais, especialmente por causa dos protestos de grupos de interesse comercial sobre o impacto económico resultante da demora nas tomadas de decisões causadas principalmente pelas exigências legais para a participação. Por outro lado, o autor 
argumenta também que para muitos membros do governo, o controle da comunidade pode ser visto como uma perda do seu poder e controle sobre o processo de planeamento. Assim sendo:

[...] o grau de envolvimento público no planeamento turístico em quase todo o mundo pode ser mais bem descrito como forma de concessões simbólicas em que as decisões, ou, igualmente importante, a direç̧ão das decisões, já foram determinadas pelo governo. As comunidades raramente têm a oportunidade de dizer não (HALL, 2004, p. 56).

Hall (2004) refere que o planeamento não é uma panaceia para todos os problemas, pois ele pode minimizar impactos potencialmente negativos, maximizar retornos económicos nos destinos e, deste modo, estimular uma resposta mais objectiva por parte da comunidade anfitriã em relação ao turismo no longo prazo. Se o planeamento se preocupa com a "antecipação e a regulamentação das mudanças no sistema, em promover de forma ordenada o desenvolvimento com o objectivo de aumentar os benefícios económicos, ambientais e sociais resultantes do processo de desenvolvimento” (MURPHY, 1985, p. 156), então o planeamento deve ser “considerado um elemento crítico para se garantir o desenvolvimento sustentável de longo prazo dos destinos turísticos” (HALL, 2004, p. 29). O desenvolvimento turístico é muito imprevisível:

[...] nunca se sabe para onde o movimento turístico se vai expandir, nunca se sabe quando vai ressurgir. Assim, por mais que haja um bom planeamento do turismo, nunca sabemos como a sociedade vai reagir à presença dos turistas, nem como os turistas vão reagir à sociedade que os hospeda. Isso traz sérias limitações ao planeamento (BARRETTO, 2005, p. 88).

O planeamento do turismo é uma tarefa complexa, uma vez que envolve aspectos relacionados com a ocupação do território, a economia, a cultura dos núcleos receptores, as características dos destinos emissores e a consequente heterogeneidade dos turistas (RUSCHMANN e WIDMER, 2000). Ou seja, o planeamento turístico é um processo “ transversal a toda a sociedade que ultrapassa os seus aspectos económicos, territoriais ou ambientais” (VIEIRA, 2007, p. 85). Ruschmann e Widmer (2000) defendem que o planeamento é essencial e indispensável para o desenvolvimento de um turismo equilibrado e em harmonia com os recursos físicos, sociais e culturais das regiões de acolhimento evitando, deste modo, que o turismo destrua as bases que o 
fazem existir. Ruschmann (2008) atesta que o planeamento do turismo sustentável emerge como uma forma de evitar a ocorrência de danos irreversíveis no turismo. Logo, a autora argumenta que o planeamento em turismo “consiste em ordenar as acções do homem sobre o território e ocupa-se em direccionar a construção de equipamentos e facilidades de forma adequada evitando, desta forma, os efeitos negativos nos recursos, que os destroem ou reduzem a sua atractividade” (RUSCHMANN, 2008, p. 9). Todavia, ressalta que o planeamento turístico "exige uma série de acções e decisões que só serão bem sucedidas se empreendidas dentro de um processo metodológico" (RUSCHMANN, 2008, p. 91). A autora acrescenta, ainda, que o planeamento turístico deve ser pautado pelos seguintes objectivos: coordenar e controlar o desenvolvimento espontâneo; promover os incentivos necessários para estimular o estabelecimento de equipamentos e serviços turísticos; maximizar os benefícios socioeconómicos e minimizar os custos, visando o bem-estar da comunidade receptora e a rentabilidade dos empreendimentos do sector; definir políticas e processos de implementação de equipamentos e actividades; garantir que os espaços necessários ao desenvolvimento turístico não sejam empregados em outras actividades económicas; evitar deficiências ou congestionamentos onerosos; minimizar a degradação dos locais e recursos sobre os quais o turismo se estrutura, e proteger aqueles que são únicos; cientificar a autoridade política responsável pela implantação de todas as implicações do planeamento; capacitar os vários serviços públicos para a actividade turística; garantir a introdução e o cumprimento dos padrões reguladores exigidos da iniciativa privada; garantir que a imagem do destino se relacione com a protecção ambiental e a qualidade dos serviços prestados; atrair financiamentos nacionais ou internacionais, bem como assistência técnica para o desenvolvimento do turismo e a preservação ambiental; coordenar o turismo com outras actividades económicas, integrando o seu desenvolvimento nos planos económicos e físicos do país (RUSCHMANN, 2008). Também Vieira (2007) refere que o planeamento do desenvolvimento do turismo deve alcançar os seguintes objectivos gerais: contribuir para a melhoria da qualidade de vida da população; promover a integração comunitária; garantir o desenvolvimento económico sustentável e proporcionar as condições necessárias para o sucesso empresarial. No que concerne aos objectivos específicos, o autor argumenta que o planeamento deve: garantir a sustentabilidade do desenvolvimento turístico; propiciar um nível elevado de satisfação 
aos turistas; proteger os recursos turísticos; identificar as zonas com potencial turístico e integrar as correntes turísticas nas comunidades anfitriãs. Assim, e de forma a procurar a optimização do fazer turístico, o planeamento em turismo engloba um "processo contínuo" baseado na “pesquisa e na acção” (DENCKER, 2004, p. 1). Todavia, para que ele apresente condições de sustentabilidade, precisa de ser orientado:

[...] tanto na sua produção quanto na avaliação por parâmetros tanto sociais quanto económicos.... Os seus objectivos deverão contemplar a optimização e a contribuição do sector do turismo e hospitalidade para melhoria da qualidade de vida das pessoas e do meio ambiente, integrando-se de forma harmónica com as demais actividades sociais e económicas (DENCKER, 2004, p. 1).

Dencker (2004) defende também que a finalidade do planeamento não deve apenas ser restringida à organização do sector para atender somente às necessidades do mercado (que têm como objectivo o crescimento económico baseado no lucro), mas também que ele deve ser orientado para a questão do plano social, considerando relações de confiança e solidariedade, de comprometimento e reciprocidade de forma a atingir interesses comuns e o estabelecimento de relações hospitaleiras. Burns (2004) desenvolveu uma abordagem bipolar, onde aponta algumas falhas e contradições do planeamento turístico. O modelo ilustra a natureza multidisciplinar das abordagens que se encontram na literatura sobre a questão: os que defendem o desenvolvimento sustentável numa perspectiva holística e os que sustentam uma visão economicista.

QUADRO I - ABORDAGEM BIPOLAR DO PLANEAMENTO TURÍSTICO

\begin{tabular}{|c|c|}
\hline $\begin{array}{c}\text { Visão Holística } \\
\text { “Desenvolvimento Primeiro” }\end{array}$ & $\begin{array}{l}\text { Visão Economicista } \\
\text { “Turismo Primeiro" }\end{array}$ \\
\hline $\begin{array}{l}\text { Desenvolvimento humano sustentável } \\
\text { - Turismo como um sistema } \\
\text { - Turismo como cultura } \\
\text { - Sistemas mundiais modernos } \\
\text { - Periferia } \\
\text { - Subdesenvolvimento }\end{array}$ & $\begin{array}{l}\text { - Crescimento económico } \\
\text { - Turismo como indústria } \\
\text { - Turismo como consumismo } \\
\text { - Globalização } \\
\text { - Núcleo } \\
\text { - Modernização }\end{array}$ \\
\hline $\begin{array}{l}\text { Visa um destino independente, diferenciado e com } \\
\text { uma dependência mínima no núcleo. Focado em } \\
\text { metas de desenvolvimento humano sustentável } \\
\text { definido pela população e conhecimento local. A } \\
\text { questão chave que conduz o desenvolvimento é: O } \\
\text { que é que o turismo nos pode dar sem nos } \\
\text { prejudicar? }\end{array}$ & $\begin{array}{l}\text { Visa a maximização do diferencial do mercado } \\
\text { através da familiarização do produto. Produto } \\
\text { homogeneizado indiferenciado, dependente do } \\
\text { núcleo com um foco em objectivos definidos pelos } \\
\text { planeadores externos e da indústria internacional } \\
\text { do turismo. }\end{array}$ \\
\hline
\end{tabular}

FONTE: BURNS (2004, p. 26) 
Para Burns (2004), as contradições e as falhas das referidas abordagens sugerem a necessidade de repensar um novo paradigma para o planeamento do turismo. Assim, sugere uma nova abordagem sustentada na designada "terceira via" que pode "fornecer uma plataforma para o crescimento sustentável e o desenvolvimento humano” (BURNS, 2004, p. 40). Nesta "terceira via”, o autor afirma que todos os actores devem participar nas diversas fases do processo: entidades públicas e privadas, visitantes e população. Todavia, o autor ressalta que "a Terceira Via no planeamento do turismo é ainda inexperiente” (BURNS, 2004, p. 38). Sintetizando, o planeamento turístico deve ser um processo integrado, contínuo, flexível, abrangente, realista, sistémico e participado (INSKEEP, 1991).

\section{CONCLUSÃO}

Conclui-se que no contexto do turismo, o planeamento é uma actividade multidimensional que se preocupa com o passado, presente e futuro. É definido como um fenómeno interdisciplinar que envolve a inter-relação de diversas componentes do produto turístico. O planeamento do turismo é uma actividade complexa que envolve diferentes partes e, por isso, está sujeito a uma série de pressões e factores que podem influenciar o processo e as pessoas nele envolvidas (OMT, 2003). O planeamento turístico é uma tarefa muito árdua, pois o seu objecto (turismo) não é fácil de apreender e, por outro lado, planear implica prever de certo modo o que vai acontecer no futuro, e este é cada vez menos previsível (BARRETTO, 2005). Se o planeamento do turismo é um processo complexo e racional, então deve ser realizado com base "num processo sistemático para que os seus resultados sejam realistas e eficazes. Este processo varia de acordo com a situação do sistema, o tipo e o nível de planeamento" (COCCOSSIS e PSYCHARIS, 2008, p. 285).

O turismo é um consumidor intensivo do espaço geográfico, ou melhor, do território e, portanto, este facto exige o planeamento do seu desenvolvimento numa óptica que evidencie de forma clara os objectivos sociais e económicos que se pretende alcançar, bem como os espaços que devem ser explorados e os que devem ser protegidos. O planeamento de um turismo sustentável promove e sustenta a relação 
interactiva que existe entre a população, a economia, o território, o ambiente e o turismo (VIEIRA, 2007).

Deste modo, as práticas de planeamento e gestão sustentável do turismo são factores de vital importância para a sustentabilidade dos lugares e a viabilidade do turismo. Se a actividade turística não for bem planeada, ela pode provocar a degradação da natureza, conflitos sociais e desorganização do sector empresarial prejudicando, deste modo, o ciclo de vida dos destinos turísticos. Por isso, o planeamento do turismo sustentável a nível regional deve levar em atenção o envolvimento de todos os actores do turismo. Só desta forma é que o planeamento minimizará os potenciais impactos negativos, maximizará os retornos económicos do destino e encorajará um maior envolvimento da comunidade receptora no turismo.

\section{REFERÊNCIAS}

ARAUJO, L.; BRAMWELL, B. Planejamento turístico regional. In: ARAUJO, L. (Org.) Geografia: espaço, tempo e planejamento. Maceió: UFAL, 2004.

BARRETTO, M. Planejamento responsável do turismo. Campinas, São Paulo: Papirus, 2005.

BENI, M. C. Análise estrutural do turismo. São Paulo: SENAC, 1997.

BURNS, P. Tourism planning - a third way? Annals of Tourism Research, v. 31, n. 1, p. 24-43, 2004.

CARVALHO, P. Planeamento, redes territoriais e novos produtos turísticos ecoculturais, 2009. Disponível em: <www.apdr.pt/congresso/2009/pdf/Sessão\%2014/91A.pdf>. Acesso em: 07/11/2009.

COCCOSSIS, H.; PSYCHARIS, Y. Regional analysis and policy: the Greek experience. Physica-Verlag (Heidelberg): Department of Planning and Regional Development University of Thessaly, 2008.

COSTA, C. An emerging tourism planning paradigm? A comparative analysis between town and tourism planning. International Journal of Tourism Research, v. 3, n. 6, p. 425-441, 2001.

COSTA, C. Um paradigma emergente na área do planeamento? Reflexão sobre questões de teoria e prática para a área do planeamento em Turismo (New paradigms for tourism planning in Portugal). In: SIMÕES, O; CRISTÓVÃO, A. (Eds.). TERN - 
Turismo em Espaços Rurais e Naturais, Instituto Politécnico de Coimbra, Coimbra, p. 789-201, 2003.

DENCKER, A. Planejamento e gestão de hospitalidade e turismo: formulação de uma proposta. In: DENCKER, A. M. (Coord.). Planejamento e gestão em turismo e hospitalidade. São Paulo: Thomson Pioneira, 2004.

DREDGE, D. Destination place planning and design. Annals of Tourism Research, v. 6, n. 4, p. 772-791, 1999.

GETZ, D. Models in tourism planning: towards integration of theory and practice. Tourism Management, v. 7, n. 1, p. 21-32, 1986.

GODFREY, K. Towards sustainability? Tourism in the Republic of Cyprus. In: HARRISON, L.; HUSBANDS, W. (Eds.). Practicing responsible tourism: international case studies in tourism planning, policy and development. Chichester: John Wiley and Sons, 1996.

GUNN, C. Emergence of effective tourism planning and development. In: SEATON, A. (Ed.) Tourism: the state of the art. Chichester: Wiley, 1994. p. 10-19.

GUNN, C.; VAR, T. Tourism planning: basics, concepts, cases. New York: Routledge, 2002.

HALL, C. Planejamento turístico: políticas, processos e relacionamentos. São Paulo: Contexto, 2004.

HALL, C.; PAGE, S. The geography of tourism and recreation: environment, place and space. 3. ed. London: Routledge, 2006.

HENRIQUES, C. Turismo, cidade e cultura: planeamento e gestão sustentável. Lisboa: Edições Sílabo, 2003.

INSKEEP, E. Tourism planning: an integrated and sustainable development Approach. New York: Van Nostrand Reinhold, 1991.

KNOWLES, T.; DIAMANTIS, D.; EL-MOURHABI, J. The globalization of tourism and hospitality: a strategic perspective. South-Western: CENGAGE Learning, 2004.

MARUJO, M. Turismo e comunicação. Castelo Branco: RVJeditores, 2008.

MASON, P. Tourism impacts, planning and management. London: ButterworthHeinemann, 2003.

MURPHY, P. Tourism: a community approach. New York: Metheum, 1985.

OMT Turismo internacional: uma perspectiva global. 2. ed. São Paulo: Bookman, 2003. 
RUSCHMANN, D. Turismo e planejamento sustentável: a protecção do meio ambiente. São Paulo: Papirus, 2008.

RUSCHMANN, D.; WIDMER, G. Planejamento turístico. In: ANSARAH, M. (Org.), Turismo: como aprender, como ensinar, São Paulo: SENAC, 2000.

SACHS, I. Estratégias de transição para o Século XXI. In: BURSZTYN, M. (Org.). Para Pensar o Desenvolvimento Sustentável. São Paulo: Brasiliense, 1993.

SILVEIRA, M. A. T. da. Planejamento territorial e dinâmica local: bases para o turismo sustentável. In: RODRIGUES, A. B. (Org.). Turismo e desenvolvimento local. São Paulo: HUCITEC, 2002. p. 87-98.

TOSUN, C.; JENKINS, L. Regional planning approaches to tourism development. Tourism Management, v. 17, n. 7, p. 519-531, 1996.

VIEIRA, J. Planeamento e ordenamento territorial do turismo: uma perspectiva estratégica. Lisboa-São Paulo: Editorial Verbo, 2007.

WILLIAMS, S. Tourism geography: a new synthesis. London and New York: Routledge, 2009.

Recebido em: 27/07/2010

Aprovado em: 26/08/2010 